\title{
A EDUCAÇÃO CORPORAL EM BADEN-POWELL: O MOVIMENTO ESCOTEIRO CONTRA O INTELECTUALISMO ESCOLAR ${ }^{1}$
}

\author{
Carlos Herold Junior \\ UNICENTRO \\ carlosherold@hotmail.com
}

Alexandre Fernandez Vaz

UFSC

alexfvaz@uol.com.br

\section{RESUMO}

O objetivo principal deste estudo é analisar o pensamento de Baden-Powell, fundador do escotismo. Para esse fim, utilizamos livros escritos pelo chefe escoteiro entre 1908 a 1939, dando especial atenção à leitura que ele fez de sua realidade e da importância da educação do corpo praticada no escotismo. Dividimos o texto em três partes: na primeira, vemos como Baden-Powell analisava o contexto no qual viveu e destacamos os problemas morais que ele enxergava na sua sociedade. Em seguida, estudamos suas críticas dirigidas à educação então existente na Inglaterra. Finalmente, examinamos como o escotismo foi visto como uma proposta para contornar os tais problemas. Como conclusão, constatamos que uma das bases da expansão do escotismo nas primeiras décadas do século XX, é a importância atribuída por Baden-Powell ao desenvolvimento da saúde, força e virilidade, cultivadas por meio de várias atividades corporais.

Palavras-chave: Corpo; Baden-Powell; Escotismo; História da Educação.

\section{BODY EDUCATION IN BADEN-POWELL: SCOUTING AGAINST SCHOOL INTELLECTUALISM.}

\begin{abstract}
The main goal of this study is to analyze the thought of Baden-Powell, founder of Scouting. To this end, we used books written by the chief scout between 1908 and 1939, giving special attention to the reading he did of his reality and the importance of body education practiced by Scouting. We divided the text into three different parts: firstly, we see how Baden-Powell analyzes the context in which he lived and we highlight the moral problems he saw in his society. Then, we study the criticisms that he addressed to education then existing in England. Finally, we examine how Scouting was considered as a proposal to circumvent those problems. In conclusion, we found that one of the bases of Scouting expansion in the first decades of the twentieth century is the importance ascribed by Baden-Powell to the development of health, strength and virility, cultivated through various bodily activities.
\end{abstract}

Key-words: Body; Baden-Powell; Scouting; History of Education.

\section{Considerações iniciais}

O surgimento e a expansão do movimento escoteiro a partir de 1907 são fenômenos particulares na história das práticas e das ideias educacionais, em especial pela rapidez com que o movimento atingiu escala planetária. No Brasil o escotismo teve seu início já em 1910 (Blower, 1994), e a mesma velocidade pôde ser vista em outras partes do mundo, 
ecoando a força do movimento no seu país de origem. Macdonald (1993) mostra que na Inglaterra havia 60.000 escoteiros em 1909. Esse número chegou a $194.000 \mathrm{em} 1917$.

Importante para esse crescimento foi o escotismo ter lidado com muitas problemáticas sociais e políticas no início do século XX, indo ao encontro de muitas expectativas voltadas para a concretização de vários projetos sociais então existentes. Entre esses desejos e projetos, havia os relacionados à expansão econômica imperialista e ao belicismo iminente. Para torná-los realidade, entretanto, foi necessário encarar a constatação de que os homens (sobretudo, os homens) estariam sendo corrompidos por um "excesso de civilização" (Macdonald, 1993, p.26). A mesma civilização vista como valiosa para ser "transmitida" como modelo aos "incultos", também poderia se transformar em obliteradora e cultivadora de vícios. Estes poriam em cheque a viabilidade de existência da própria civilização, levantando dúvidas sobre a possibilidade, a necessidade e o sucesso de sua "transmissão". Por isso, gestado em um momento expansivo da "civilização européia", o escotismo foi importante por lutar contra os efeitos negativos trazidos por esses valores, deles cuidando por se assumir como justificáveis os interesses de um país de ambições imperiais.

Ao lado dessas problemáticas mais amplas que ajudam a justificar a força das ideias e das práticas escoteiras, há questões relativas à organização e à condução do escotismo, fundamentais para a construção dessa importância. Desde seu início, o escotismo lançou mão de estratégias de divulgação que exploraram amplamente os recursos impressos então disponíveis (Macdonald, 1993, p.10; Proctor, 2002, p.14). Nesses impressos, dentre os modos utilizados para divulgar suas ambições formativas, observamos o uso da imagem de seu fundador, Robert Smyth Stephenson Baden-Powell (1857-1941). Jeal (2001) nota que as vitórias militares de Baden-Powell nas guerras imperialistas na África do Sul o fizeram alcançar grande popularidade na Inglaterra. Os traços pessoais do general, bem como tudo o que ele dizia à imprensa, eram avaliados como elogiosos e portadores de autoridade. Dentre as características divulgadas à imprensa e consideradas como a causa de suas vitórias militares, Jeal (2001) sublinha aquelas que faziam de Baden-Powell uma espécie de "Peter-Pan", uma eterna criança apaixonada pela vida ao ar livre e pelos jogos. Ele era elogiado por seu envolvimento e empolgação infantis em suas ocupações diárias, tanto aquelas do âmbito doméstico, das escolas que frequentou como aluno, dos agrupamentos militares que tomou parte e liderou, bem como na sua atuação como líder mundial do escotismo. Mesmo Rosenthal (1986), um analista crítico do movimento e de seu fundador, não deixa de ver que "Baden-Powell sabia como revestir princípios abstratos com exemplos cativantes" ${ }^{23}$ (p.125).

No contexto brasileiro, a figura de Baden-Powell também foi importante para divulgação do movimento. Para termos um exemplo, citamos a passagem de um jornal que circulou no interior do Paraná para divulgar o escotismo em 1929: nele, Baden-Powell é descrito como um grande exemplo a ser seguido...

Nosso chefe é realmente um homem original. Tem 73 annos. Acorda, todos os dias, ás cinco e meia. Escreve livros. Passa uma boa parte de seu tempo a esculpir, a pintar e a desenhar. Ainda recentemente modelou lindos bustos de seus filhos. Quando desenha, utiliza-se, indistinctamente, de uma e outra mão (dizem que quando tem pressa, faz ao mesmo tempo, um desenho com a mão direita e outro com a mão esquerda) (apud Herold Junior, 2011, p. 140).

Ao lado do reconhecimento da relevância histórica do movimento escoteiro e sua expansão sustentada na credibilidade que a imagem de Baden-Powell oferecia às 
promessas formativas que propunha, não devemos desconsiderar a existência de análises problematizadoras de certas facetas desse crescimento e expansão relacionados à pessoa de Baden-Powell. Macleod (1983) e Proctor (2002) questionam os estudos sobre os movimentos de educação para a juventude, pelo fato de eles terem se pautado apenas nos discursos de seus proponentes ou de seus legitimadores. Esse traço acabou, dizem esses historiadores, proporcionando uma visão muito influenciada pela vontade de querer ver os preceitos de seus líderes e defensores realizados, diretamente, no aumento exponencial do número de escoteiros que aconteceu nas primeiras décadas do século XX. Macleod (1983) não desconsidera que "O crescimento do escotismo foi parte de uma tendência mundial [...] para lidar com a rápida mudança cultural introduzindo os jovens em um mundo supervisionado de recreação com valores pré-fabricados" ${ }^{4}$ (Macleod, 1983, p.183). Além disso, Childs (1995) lembra que "O período de 1890 a 1914 viu uma eflorescência de tais organizações e instituições, atendendo a uma quantidade de cada vez maior de jovens e usando métodos cada vez mais sutis e sofisticados para atrair e manter a lealdade desses rapazes" "Childs, 1995, p.140). Entretanto, pondera-se que os chamados "construtores de caráter" "...frequentemente (eles) foram melhores em conquistar o apoio dos adultos a reter os rapazes"6 (Macleod, 1983, p. 56).

O esforço de se construir olhares matizados sobre a história do escotismo também pode ser notado no Brasil. Os trabalhos de Souza (2000, 2009), Zuquim e Cytrynowicz (2002), Nascimento (2004), Nascimento (2008), Herold Junior (2011), Thomé (2006, 2010) e Gabriel (2003) são representativos dos caminhos percorridos pela produção acadêmica referente à história do escotismo. Neles, podemos ver a expansão do escotismo ligado à ideologia nacionalista e militar no Brasil (Souza, 2000; Zuquim e Cytrynowicz, 2002; Thomé, 2006), bem como aproximada de questões especificamente educacionais (Souza, 2009; Thomé, 2010; Nascimento, 2008; Gabriel, 2003; Herold Junior, 2011).

Tanto os elementos levantados pelos analistas internacionais da história do escotismo, quanto às problemáticas estudadas pelos estudiosos brasileiros acima citados, são assumidos como estímulos para pensarmos a relevância de Baden-Powell para a história das ideias e das práticas educacionais no início do século XX. Por isso, com o fito de colaborar com a construção de um maior entendimento sobre esse movimento formativo de jovens, somamos nossos esforços aos estudos já existentes, apresentando este trabalho com o seguinte objetivo: analisar no pensamento de Baden-Powell a forma como ele concebeu o movimento escoteiro em relação à situação da sociedade na qual ele se inseria, articulando a contribuição do escotismo à correção e/ou complementação de outras práticas educacionais então existentes. Partimos da hipótese de que Baden-Powell justificava a importância do escotismo por fazer frente à exagerada valorização da formação intelectual que ele via existir nas instituições educacionais, combatendo-a por meio de uma grande atenção às atividades do corpo, fomentadas pelo escotismo.

Dentre os esforços de pesquisas sobre a história do escotismo no Brasil, apenas as análises de Nascimento (2008) focalizam, de forma mais detida, os textos de BadenPowell. Essa atenção levou Nascimento (2008) a defender a existência de uma "escola de Baden-Powell". Aqui, propomos ampliar a reflexão sobre as ideias dessa "escola", investigando-as a partir de uma lacuna tocante à história da educação do corpo e da educação física, lacuna essa também observada no importante estudo de Nascimento (2008). Nos poucos trabalhos que abordam a educação corporal escoteira, ela não é escrutinada como um de seus principais objetivos e/ou não utilizam, diretamente, a obra de Baden-Powell nem como fonte nem como objeto (Ferreira Neto e Neitzel, 2006; Puchta, 2007; Scharadgrodsky, 2008; Taborda de Oliveira, 2007; Linhales, 2009). A educação corporal no escotismo foi analisada no contexto indiano por Watt (2009), no argentino 
Scharadgrodsky (2008) e por Herold Junior (2011), no Brasil. Entretanto, esses trabalhos não relacionam a educação do corpo com as perspectivas de Baden-Powell sobre a sociedade e a educação de forma geral, manifestas nos livros e artigos redigidos pelo fundador do movimento escoteiro.

Por isso, o presente estudo investiga as questões acima nas obras de Baden-Powell, abarcando livros por ele produzidos no período de 1908 a $1939^{7}$. Essas reflexões foram organizadas em uma estrutura narrativa composta por três partes: na primeira, verificamos a maneira como Baden-Powell analisa seu contexto e destacamos os problemas morais por ele encarados. Depois, estudamos as críticas que ele endereçava à educação existente na Inglaterra, notando que o principal problema levantado era o que ele chamava, pejorativamente, de intelectualismo, presente nas práticas escolares. Por fim, verificamos o modo como o escotismo colocou-se como proposta para contornar essa dificuldade ao indicar práticas e ideias cultivadoras da saúde, da coragem e da virilidade.

\section{Constatando a crise moral da sociedade pela fraqueza do corpo individual e social.}

Baden-Powell justificava sua preocupação formativa pelo fato de ela fazer frente a uma tendência já perceptível em seu tempo: a diminuição do volume de esforços físicos necessários para resolver os problemas da vida cotidiana e as consequências que essa facilidade teria na composição moral dos cidadãos. A aplicação do conhecimento científico no aumento do conforto era avaliada como causa de um declínio na constituição dos homens: “.... civilização, com sua vida urbana, bondes, água quente e fria disponível, tudo feito para você, tende a tornar os homens moles e fúteis" ${ }^{8}$ (Baden-Powell, 1922, p. 10). A lista de coisas a serem evitadas aumentava com o avanço da civilização. Essa mudança avaliada como prejudicial por Baden-Powell deveria ser freada, justificando a necessidade de se pensar na educação dos futuros cidadãos como condição para se contornar uma decadência nacional, já vista como palpável:

O público é demasiadamente ocupado com as estrelas do cinema, jogos, finais de campeonatos e assassinatos. Tem sido assim, há algum tempo: e graças e esse interesse em um valor falso a nação tem sofrido hoje de muitos males. Se o país quiser se livrar dessa desgraça que a obscurece, ela deve se livrar das pocilgas e da miséria e da imundície que atinge a massa de seu povo. Deve ajudá-los em sua total falta de religião e felicidade. Deve despertá-los para a necessidade de uma educação mais verdadeira para as próximas gerações de cidadãos. O sucesso ou o fracasso de nossa nação repousa nas mãos daqueles que hoje são meninos e meninos ${ }^{9}$ (Baden-Powell, 1929, p. 6).

Baden-Powell também via como fonte de vícios e enfraquecimento o aumento da circulação de notícias e de imagens. Além delas, as apostas em competições esportivas ou o consumo do tempo de lazer assistindo a jogos e competições eram fatos que o levavam a clamar por uma reflexão mais atenta à educação da juventude. $\mathrm{O}$ potencial danificador dessas práticas se dava por sua ocorrência coletivizada nos grandes centros: “.... educação hoje lida com grandes dificuldades na forma de um certo instinto de multidão, ensinamentos indesejáveis da imprensa sensacionalista, filmes imorais e fácil acesso às apostas e à prazeres baratos e danosos à saúde ${ }^{10}$ (Baden-Powell, 1933, p. 273).

A inquietação de constatar que o artifício substituía a natureza era um leitmotiv de Baden-Powell. O excesso de máquinas, de amontoados populacionais que "corriam" apenas em busca da satisfação imediata de seus apetites, era o que ele chamava, em tom de 
crítica, de materialismo. Para agravar a situação, a esse estado de coisas era adicionada a ideia de que esses desvios da natureza, no final das contas, também afastavam o homem de Deus:

Com a moderna extensão das cidades, burgos e fábricas, com suas grandes estradas asfaltadas, telégrafo, telefones e linhas elétricas sob a superfície do país, a civilização está conduzindo a natureza cada vez mais longe do alcance da maioria, de modo que até a compreensão das suas belezas e maravilhas, bem como nossa afinidade com as criaturas de Deus estão se perdendo na vida materialista da multidão, com suas condições deprimentes de trabalho e desesperada busca de prazeres em meio a um ambiente deplorável de tijolos e argamassa. O artificial está inundando o natural em nossa vida; graças aos carros motorizados, bicicletas e elevadores, nossos membros, assim como nossos espíritos, atrofiarão pela falta de exercício e nossos se tornarão cérebros ao invés de músculos ${ }^{11}$ (Baden-Powell, 1933, p. 273).

A natureza estaria, então, sendo suplantada por falsidades aniquiladoras do ímpeto de luta e do autoaperfeiçoamento corpóreo e moral. Essas falsidades eram tomadas como apanágios do "excesso de civilização", marca das grandes cidades com suas multidões. As cidades seriam lugares nos quais muitos dos sentimentos e atitudes corretas existentes no passado, não tinham mais espaço:

Em nossos populosos e modernos centros, estamos, rapidamente, tornando-nos demasiadamente civilizados. Tem sido dito que em poucos séculos nossas pernas se atrofiarão por meio de uma completa dependência de metrôs, bondes e ônibus. Nossos caracteres, também, não estão melhores por ter tudo pensado e feito fácil para nós, afinal iniciativa, desenvoltura, autoconfiança, coragem, bravura e outras virtudes não serão mais solicitadas. Nós seremos uma nação de molengas. $\mathrm{O}$ artificial está expulsando o natural e em poucas coisas isso é, realmente, bom para nós ${ }^{12}$ (Baden-Powell, 1929, p. 16).

Baden-Powell, então, avaliava as dificuldades resultantes das pressões advindas da "vida coletiva" das cidades, enfrentadas pelas pessoas. Esses problemas, chamados de "rocks", agiam sobre os homens e os levavam à preguiça, à depravação e à falta de patriotismo. Eloquente é a forma como as "rocks" são listadas: "AS PEDRAS [dificuldades] (Por meio da tentação do rebanho). Cavalos, apostas, e assistir a falso esporte. Vinho, e outras formas de autoindulgência ${ }^{13}$. Mulheres, perigos das atitudes erradas e as bênçãos das corretas. Extremistas em política, em religião, etc ${ }^{14 \text { " }}$ (BadenPowell, 1922, p. 108).

Jeal (2001) capta a relação entre o pensamento de Baden-Powell e a forma como a sociedade se compunha no início do século XX. O que causava grande dificuldade ao movimento, ao mesmo tempo em que era a sua grande razão de ser, era a defesa de um determinado "common sense": a importância da natureza, da vida simples e da vontade de ajudar ao próximo. Um "common sense" deixado de lado pela vida em um contexto onde os valores praticados eram, exatamente, os opostos:

Muito conhecimento mata o bom senso, ele escreveu confiantemente, dando como exemplos a intuitiva habilidade de construtores de pontes no Oeste da África que podiam cobrir um rio utilizando apenas parte do 
tempo utilizado pelos engenheiros britânicos, com seus "cálculos complexos". Mas a futura prosperidade de nações industriais depende mais de seus cientistas do que de seus colonizadores autoconfiantes e exploradores heróicos. Isso não importando quão fortes sejam seus músculos e vigorosos seus caracteres. Essa foi a impalatável verdade que os escoteiros capacitaram a muitos ignorar: o cérebro na moderna sociedade importa mais que o caráter, não importando o decreto dos examinadores da Bolsa Rhodes [bolsas de estudos a estudantes da Universidade de Oxford]. Uma civilização dominada pela tecnologia apenas teria sucesso em colaborar mais com homens formados no valor da ciência e do conhecimento, aqueles encorajados a desprezá-los. ${ }^{15}$ (Jeal, 2001, p. 420).

$\mathrm{O}$ conjunto de transformações visíveis na sociedade das primeiras décadas do século XX tocava muitas dimensões que influenciavam a temática educacional. As mudanças nas relações pessoais entre homens e mulheres, ocasionadas pelas alterações do estatuto social da mulher, era uma delas. De acordo com Jeal (2001), Baden-Powell avaliava algumas das reivindicações femininas ${ }^{16}$ como resultado do enfraquecimento da virilidade, solapada pela decadência dos hábitos. Essa situação deveria ser revertida por uma educação, de fato, masculina e masculinizante:

Com as mulheres agora entrando em profissões e as sufragistas destruindo aquele reconfortante estereótipo da mulher gentil e atenciosa, os homens começaram a vislumbrar um futuro em que as mulheres sejam capazes de fazer seus trabalhos e em que não haveria mais espaço para carreiras que exijam força e resistência. Na América os novos imigrantes eram crias diferentes da antiga cepa; era isso uma culpa de mulheres melhor educadas, ou era a deterioração urbana que exauria a virilidade dos homens ricos que vivem nas cidades? ${ }^{17}$ (Jeal, 2001, p. 411)

No interior desse amplo processo de observação da relação entre o que era natural e o que era artificial, diz Baubérot (2004) que o corpo tornou-se um alvo de reflexão muito recorrente. À forma como as transformações sociais eram percebidas, deveriam se somar os avanços científicos que deram ao corpo visibilidade e grande importância na construção de um novo modelo de controle social.

É possível notar a maneira como os caminhos seguidos pela ciência construíram uma nova "sensibilidade corporal" quando observamos as consequências que nisso teve a publicação da teoria da evolução das espécies, de Charles Darwin. Para Baubérot (2004): "As teses evolucionistas, pelo contrário, acabaram a imagem de um corpo imóvel, reproduzindo-se identicamente desde a noite dos tempos, para fazê-lo um objeto movente, instável, suscetível de se transformar sobre a influência de seu ambiente"18 (Baubérot, 2004, p. 140). Uma vez não ser mais sustentável a ideia de imutabilidade do corpo no decorrer das eras geológicas e dos processos de especiação, Baubérot (2004, p.140) observa o surgimento de uma responsabilidade pessoal perante a situação tanto do corpo individual, quanto do "corpo" social. Nesse ínterim, a avaliação feita por Baden-Powell das mazelas sociais que testemunhava extrapolava a dimensão diretamente educativa e tocava as regras de conduta da sociedade como um todo. Não importando o problema constatado, era a aptidão física cuidada e desenvolvida o alvo necessário para a reabilitação da "nação":

Quem bebe é um perigo ao Estado. A proibição não será necessária onde a nação consistir de homens de caráter. A força do exemplo. Fumar em 
demasia é um perigo para a saúde, assim como outras formas de autoindulgência, tal como comer bastante. Dormir mais que o necessário. Trabalhar além da conta. Aptidão física proporciona autocontrole e vida longa. Fazer promessas é um sinal de fraqueza no caráter ${ }^{19}$ (BadenPowell, 1922, p. 31).

A situação belicosa das primeiras décadas do século XX também ofereceu bases para se pensar na necessidade de melhorar a educação incrementando a aptidão física. Baden-Powell lembrava-se que em 1914, entre os poucos voluntários para defender sua pátria, muitos eram recusados por conta de sua incapacidade de levar a cabo as mais simples exigências da vida militar. Essa constatação era um importante ponto de apoio na defesa da utilidade do escotismo:

No começo da Guerra européia de 1914, dois milhões de nossos homens alistaram-se voluntariamente. Seis milhões não o fizeram. Um milhão foi incapaz de fazê-lo, devido a defeitos físicos originados por causas previsíveis. [...] Nosso objetivo no escotismo (e no bandeirantismo) é desenvolver ambos e ajudar a próxima geração a se tornar cidadãos eficientes e felizes ${ }^{20}$ (Baden-Powell, 1929, p. 13).

Esse estado de decadência moral visto na languidez corporal era verificado como espalhado em toda a sociedade. Abordá-lo, porém, demandava a redução do foco analítico para o que, mais imediatamente, poderia alterar essa situação: as práticas educacionais. Esse olhar demonstrava que a educação também precisava alterar seus rumos.

\section{Os limites da educação: o intelectualismo e a desconsideração da educação corporal.}

Baden-Powell justificava boa parte de seu programa escoteiro fazendo críticas à educação de sua época. Elas eram dirigidas tanto às estruturas especificamente escolares, quanto aos hábitos e aos procedimentos da educação doméstica. Esta seria também responsável pelo estado de decadência moral e física diagnosticado.

Era constatada uma situação de calamidade moral e física que assolava a Inglaterra, gerada pela desatenção aos assuntos educacionais. Revertido esse estado ao receber a educação maior consideração, estaria colocada uma das condições para que os males apontados deixassem de existir. Porém, não se tratava, apenas, de melhorar a educação da dimensão intelectual. Para que ela tocasse as dimensões morais e físicas, fazia-se imperativo à educação assumir características mais amplas:

Educação é uma grande garantia. Por educação eu não quero dizer grande cultura, mas educação da mente e da alma. Aquela que capacita você a passar pelo perigo; a educação da alma empurra você acima dele. Se você expande sua mente dando para você mesmo um conhecimento mais amplo por meio de viagens e leituras, por meio do aprendizado que se tem da experiência com os outros, e do estudo da natureza, você estará a salvo da estupidez, se você expandir sua alma dando-se ideais superiores e aos outros sua solidariedade por meio da boa vontade e de sua solicitude, você nunca será nem um tolo, nem um erudito, mas se perceberá como um homem melhor e mais feliz ${ }^{21}$ (Baden-Powell, 1922, p. 79). 
A análise das mazelas não se reduzia aos aspectos mais amplos dos fins a que se destinava a educação. A dinâmica escolar era avaliada como plena em empecilhos à realização de ambições educacionais mais completas e condizentes às necessidades do tempo. Baden-Powell (1929) sublinhava a impossibilidade de serem instilados valores elevados em uma sala de aula repleta de alunos, todos aos cuidados de apenas um professor. Nessa situação, os alunos eram tratados como massa, multidão. Por si só, isso tornava a escola um solo fértil para o florescimento de vícios e fraquezas:

O professor não pode esperar, no tempo disponível, fazer mais que mostrar às crianças os elementos e inculcar-lhes o desejo e o método de aprender por eles mesmos. O professor de hoje reconhece, plenamente, a necessidade do treinamento do caráter, mas atrapalhado pela impossibilidade de ensinar o caráter para uma classe grande. Treinamento de caráter é uma questão de determinar e desenvolver por meio da melhor habilidade do professor essa origem do bem que existe em cada criança, individualmente; mas o professor, acossado por uma classe de quarenta a sessenta crianças não pode esperar lidar com elas de outro jeito que não seja como uma multidão ${ }^{22}$ (Baden-Powell, 1929, p. 7).

Com efeito, o pensamento de Baden-Powell, dirigido ao grande público de jovens, professores e adultos preocupados com a formação da juventude, não perdia a oportunidade de relacionar a crise moral com a criticável ênfase posta pela escola no aprendizado intelectual. Além disso, ele também reprovava a tendência, muito presente em seu tempo, de militarizar a educação. Essa característica era identificada na constante prática de organizar paradas e desfiles com os alunos ${ }^{23}$. No final das contas, conclui Baden-Powell, essa preocupação intelectualista e a ânsia de arranjar os jovens para os desfiles, explicitava a decadência da sociedade, reforçando-a desse modo. Essa insistência, de um lado, na razão e, de outro, na pompa militar, era avaliada como inibidora da coragem e do gosto pela aventura, sentimentos diluídos no rebaixado nivelamento individual à multidão:

...estimável moço, capaz de ler e escrever, bem comportado, dócil à disciplina, que facilmente imita o olhar imponente dos soldados durante as paradas - mas sem individualidade ou força de caráter, totalmente sem engenhosidade, iniciativa ou coragem para a aventura. As condições modernas de vida com sua artificialidade os fazem membros de um rebanho com tudo feito para eles e com o fetiche do "primeiro minha segurança" diante de seus olhos ${ }^{24}$ (Baden-Powell, 1933, p. 272).

Os esforços educacionais, ao se perderem no âmbito da aglomeração ou da massa, acabariam por fomentar o individualismo do "my safety first". Isso ocorria também na educação feminina, que Baden-Powell (1933) escrutinava de forma a enxergar avanços, mas, igualmente à educação de forma geral, era prejudicada pela característica intelectualista cultivada em grandes grupos. Para o indivíduo esse rumo educacional apenas redundava no desenvolvimento de sentimentos negativos, tais como apatia, fraqueza e desconsideração aos valores morais. A educação possível era a que se ocupasse de cada indivíduo como meio de formá-lo para as responsabilidades cívicas:

A educação escolar das meninas foi colocada em um ritmo maior de melhoramento, mas o problema do treinamento do seu caráter ainda está sem solução. O caráter não pode ser treinado em uma classe. Ele deve 
ser, necessariamente, expandido no indivíduo, e na maioria do tempo por meio do esforço da parte da própria aluna ${ }^{25}$ (Baden-Powell, 1933, p. 302).

Mesmo que aos professores e à escola fosse imputada a culpa de equivocadamente sublinharem o intelectualismo deformador do caráter, Baden-Powell (1939) notava todo um ambiente grandemente corruptor da natureza humana em seu tempo. Isso fazia o exgeneral lamentar que as próprias crianças e jovens desde muito cedo influenciadas por esses vícios, acabassem por preferir os conhecimentos materializados nos livros. Elas deixavam de lado os saberes acumulados no dia-a-dia, na experiência, nas atividades do corpo, fundamentais para a reconstrução moral da sociedade. Baden-Powell (1939) compreendia a desconsideração pela coragem, patriotismo e saúde pelo fato de o já mencionado "common sense" ser visto como inútil: "Bom senso é quase a coisa mais útil e valiosa que você em seu caráter. O lamentável é que poucos colegas sabem disso ou fazem uso dele. Eles preferem ser guiados pelo o que eles vêem escrito nos livros ao invés de seu próprio juízo" ${ }^{26}$ (Baden-Powell, 1939, p. 20).

Jeal (2001) também observa em Banden-Powell uma grande repulsa ao intelectualismo, levando o fundador do escotismo a não poupar avaliações negativas às escolas, mesmo as mais modernas. Ao funcionarem nas grandes cidades, nelas se aprenderia o valor atribuído ao intelecto em detrimento de uma formação mais autêntica do caráter, baseada na ação e nas atividades do corpo: "Essa combinação do anti-intelectual com o anti-urbano encaixou-se com as críticas de Baden-Powell às escolas por sua negligência ao desenvolvimento físico e moral dos garotos" ${ }^{27}$ (Jeal, 2001, p. 359). E se a consideração pelo fortalecimento corporal existisse, ele era baseada em pressupostos equivocados: "Há uma grande estupidez em voga no que tange aos exercícios corporais; muitas pessoas parecem pensar que o único objetivo desses exercícios é fazer músculos grandes" 28 (Baden-Powell, 1908, p. 212).

Essas dificuldades da escola em atender às urgências educacionais das primeiras décadas do século XX não eram vistas como totalmente incontornáveis. Afinal, tratava-se de verificar aquilo de que careciam os alunos para fazê-los aproveitar bem e utilmente suas vidas. Nesse sentido, muitos dos conteúdos ensinados eram desnecessários e a insistência no seu ensino era vista como mostra de grande ignorância:

Impor a gramática grega ou latina a jovens nenhum um pouco interessados nelas, parece-me ser uma estúpida perda de tempo, assim como fazer moças sem dom para a música gastar horas intermináveis aprendendo as escalas no piano. Eu sei que eu estou demonstrando minha ignorância na ciência e na teoria da educação dizendo isso, mas eu estou simplesmente falando a partir dos resultados que tenho visto no mundo ${ }^{29}$ (Baden-Powell, 1933, p. 21).

Muitos desses problemas, de alguma maneira, eram percebidos por aqueles que pensavam e trabalhavam nas instituições educacionais. Porém, para Baden-Powell, apesar de a educação ser alvo de grandes investimentos, estes eram dirigidos a um rumo equivocado. Esse erro constituía-se na valorização excessiva no mero domínio de informações e na negligência de dimensões de grande relevância para a vida. $\mathrm{O}$ resultado dessa situação era que toda a preocupação educacional formava pessoas mais próximas aos vícios, às doenças, ao egoísmo e à contravenção, e não pessoas plenas de virtudes condizentes com a construção de uma nação à altura das expectativas elaboradas pelas gerações anteriores. Essas expectativas eram sustentadas pela expansão imperialista 
britânica conquistada no passado, mas posta em risco pela decadência moral resultante dos equívocos educacionais:

Se observarmos a quantidade de dinheiro público que é gasto todo ano em educação, e, então, notarmos a proporção de problemas de saúde, de doenças previsíveis, mortalidade infantil, crime, desemprego, a pobreza perdulária e incapaz de trabalho, o que nenhuma quantidade de dinheiro público pode resolver, tudo isso dominando a população do tempo presente, com toda honestidade nós temos que admitir que a finalidade da educação ainda não foi atingida. [...] Talvez, a educação de uma ou duas décadas atrás - da qual hoje vemos os resultados - tendeu muito à realização escolástica e muito pouco a ser uma preparação para a vida. É a educação para vida que é necessária, desde que realizações escolásticas ajudam apenas um pouco, enquanto a vida tem de ser vivida por cada indivíduo que nasce no mundo. A educação ainda tende a preparar os meninos e as meninas para os padrões dos exames, mais que para as necessidades da vida; e por vida quero dizer não meramente como ganhar a vida, mas como viver- como aproveitar e tirar o melhor proveito da vida, ser feliz e útil ${ }^{30}$ (Baden-Powell, 1929, p.7).

Ou seja, via-se alguns melhoramentos acontecendo nas últimas décadas. Não se tratava de falta de conhecimento sobre o quê e como fazer, mas sim de lutar contra hábitos e métodos utilizados, persistentemente, pelas escolas:

O progresso e a melhora da educação tiveram desenvolvimento nesta última metade de século, desde a época em que eu estava na escola, mas métodos tradicionais não desaparecem facilmente, e eles falham no que deveriam fazer: produzir os muitos líderes ou os servidores da sociedade capazes, dos milhares de jovens que a escola manda para mundo a cada ano $^{31}$ (Baden-Powell, 1933, p.21).

Desse modo, não era secundarizada a existência de caminhos possíveis para sua "cura". Os "antidotes", contrariamente as "rocks", agiriam apenas por meio do esforço individual relacionado ao trabalho, à ação e à saúde, postos a serviço da comunidade e de Deus: "ANTÍDOTOS (Por meio do esforço individual) Passatempos ativos e o ganho do dinheiro. Autocontrole e caráter. Bravura e saúde da mente e do corpo. Trabalho para seus companheiros e para Deus" ${ }^{32}$ (Baden-Powell, 1922, p.108).

\section{A importância do escotismo para remediar ou completar a educação escolar por meio da educação do corpo.}

Para Baden-Powell (1933) pensar a educação era uma tentativa de expandir os limites da escola, visualizando todas as situações em que a verdadeira aprendizagem pudesse ocorrer. Por isso, o grande valor dado aos momentos de lazer e/ou descontração com os colegas. Nessas situações muitos dos nobres sentimentos e ideais eram visualizados, aprendidos e postos em prática: "Somando ao que eu aprendi quando ia à escola - o que não foi tanto assim - havia o uma grande quantidade de coisas que aprendi quanto estava na escola, fora da sala de aula, momentos muito valiosos. Eu também aprendi mais nas férias, com meus irmãos"33 (Baden-Powell, 1933, p. 23). Consequentemente, é compreensível que ele avaliasse os espaços de lazer e de prática de esportes como lugares privilegiados na construção da educação que almejava. Por isso, a 
seguinte afirmação: "Você frequentemente testemunha o dito de que a educação dos garotos mais abastados vai bem. Ela é boa, mas não tanto por aquilo que é ensinado na sala de aula assim por aquilo que á aprendido jogando - no campo e fora da escola" ${ }^{34}$ (BadenPowell, 1922, p. 10).

Não somente extrapolar os espaços institucionalizados da educação era visto como fundamental na busca de oportunidades realmente educativas. Buscar exemplos em outros tempos históricos também era uma ferramenta analítica utilizada no endosso das críticas e das propostas em construção. Esse procedimento consistia em olhar para distintos períodos e relacionar sua grandeza, ou seus problemas, à presença ou à falta de determinadas características intelectuais, volitivas e físicas de seus membros. O declínio do Império Romano, por exemplo, era explicado pela perda de força física: "Uma causa que contribuiu para a queda do império romano foi o fato de que os soldados perderam o nível de força corporal de seus antepassados" ${ }^{\prime 35}$ (Baden-Powell, 1908, p.208). Na maneira como os espartanos educavam seus jovens via-se uma das causas de sua grande força e coragem. $\mathrm{O}$ apelo a esse estratagema apontava para a condenação cabal do modo com o qual jovens estariam sendo educados no momento em que ele escrevia. Para a inversão da tendência formativa que redundava em homens fracos e inúteis, a lamentação de Baden-Powell é indicativa da relevância concedida à regeneração moral por meio do treinamento do corpo: "Infelizmente, para o rapaz comum dos países civilizados, não há nada desse tipo. Nós precisamos muito desse tipo de treinamento para nossos moços se quisermos manter a virilidade em nossa raça ao invés de acabar sendo uma nação de rapazes moles, desleixados e fumadores de cigarro" 36 (Baden-Powell, 1922, p.10).

Por tudo isso, o escotismo era a possibilidade de remediar os limites educacionais enfatizados. Deve ser notado que as limitações a serem superadas pelas práticas escoteiras não se circunscreviam às observadas no âmbito educacional. Nem a religião nem a política estariam em condições de fomentar os valores por muitos defendidos, mas que, na prática social, não eram vistos em ato. A esperança no escotismo como viabilizador desses sentimentos justificava-se na rápida expansão do movimento e, sobretudo, na sua possibilidade de cruzar barreiras políticas, classistas e religiosas:

A educação não tem uma perspectiva mais ampla que não seja formar escolares. [...] A cristandade ou uma prática amorosamente tolerante ainda não tem lugar nesse mundo. No escotismo e no bandeirantismo nós fazemos a tentativa de despojar todo o egoísmo instilando no jovem uma visão mais ampla, uma boa vontade mútua e o trabalho. Não fingimos que o escotismo vá resolver todos os problemas, mas sendo ele foi aceito com tal rapidez como uma fraternidade, como ocorreu em muitos países, indiferentemente de classe, credo ou raça, pode-se esperar que ele, de algum modo, é um passo definitivo ao que se deseja ${ }^{37}$ (Baden-Powell, 1933, p.312).

O escotismo também seria uma solução para os problemas de indisciplina que existiam na escola. Afinal as práticas escoteiras reverteriam a exagerada atenção aos livros e criaria situações práticas e envolventes, aproximadas à natureza dos jovens. Elas seriam aproveitadas, também, por aqueles alunos, normalmente, vistos como causadores de problemas, por não se curvarem, com facilidade, ao intelectualismo. Com efeito, essa ênfase no intelecto, concebida como antinatural, levava à revolta dos alunos. Isso era um alento às esperanças educacionais de Baden-Powell. Afinal, a indisciplina, de acordo com essas ponderações pedagógicas, era um sinal de que a inteligência juvenil se rebelava contra o artificialismo intelectual de um mundo escolar "livresco". A desobediência na 
escola era assumida como uma luta, por parte do futuro homem, para realizar sua verdadeira e inalienável vontade de aprender e de se aperfeiçoar. Por isso, o escotismo seria bom não somente para os alunos ao dar-lhes a liberdade de exercerem suas forças naturais, mas, principalmente, para o bom andamento do trabalho dos professores ao colocá-lo em consonância com essa natureza:

Esse esquema pode, assim espero, suprir de meios adicionais através dos quais podemos nos livrar dos garotos mais indisciplinados, continuando a pratica da teoria que eles aprendem na escola. Os indisciplinados frequentemente são os melhores, desde que você pega o lado correto deles. Recentemente, uma comissão em nossas escolas mostrou que há um excesso de instruções baseadas em livros na maioria delas; possivelmente, se um dia na semana fosse dedicada ao escotismo, isso seria de um grande benefício para professores e alunos, mentalmente e fisicamente $^{38}$ (Baden-Powell, 1908, p.346).

Ao contemplar essa natureza corpórea dos jovens nos momentos de aprendizagem, o escotismo não seria apenas um remédio para os problemas que se observavam no cotidiano escolar, mas também um complemento daquilo que se ensinava na escola. A preocupação com a autoformação era considerada um inestimável enriquecimento ao curto período em que os jovens passavam na escola. Por isso, o término da vida escolar era um momento fundamental para concretizar uma correta formação do homem. Ao analisar esse momento, Baden-Powell utilizava-se de metáforas, sugerindo que o aluno deixava a escola com um "palito de fósforo" para iluminar o "quarto escuro" da vida. O escotismo aumentaria a capacidade da tal "fonte de luz" iluminar o longo e tenebroso caminho. Este deveria levar, apesar todos as "rocks" no trajeto, ao exercício de uma boa profissão, da paternidade, da cidadania e da liderança sobre outros homens:

Lembre-se de que ao deixar a escola você não está totalmente educado para se tornar um homem. Principalmente, a você não foi mostrado como aprender. Se você quer conquistar o sucesso, você deve finalizar sua educação educando-se. Eu sugiro que isso deve tomar três direções, a saber: a sua profissão ou negócio, como um futuro pai, e como um cidadão líder de outros homens. Quando eu deixei a escola eu pensava que estava, como de fato estava, em uma sala escura e a educação que tinha recebido era um fósforo acesso que mostrava o quão escuro ele estava, mas lá havia uma vela disponível para eu acendê-la com esse fósforo, usando-a para me guiar, no futuro, dentro sala ${ }^{39}$ (Baden-Powell, 1922, p. 9).

O escotismo era apenas mais um dos variados movimentos e propostas formativas que objetivavam trabalhar a educação da juventude para além do mundo escolar. BadenPowell também os assumia como auxiliares, ou complementares à educação das crianças e dos jovens. Eles também abordavam a transmissão de valores desejados por meio da prática de atividades variadas em ambientes diferentes dos das grandes cidades e de suas escolas. Porém, ao falar especificamente do escotismo, quatro domínios são definidos para sublinhar a função complementar das atividades escoteiras à educação oferecida pela escola:

No treinamento escoteiro nós estamos trabalhando para preencher algumas dessas lacunas. As principais que achamos abertas são: 1)Caráter 
- ou seja, virilidade, senso de honra, um postura equilibrada e tolerante. 2) Saúde física e cuidado com o corpo por meio da temperança e castidade. 3) Trabalhos manuais e cooperação da mão com o cérebro. 3) Trabalho para os outros e para a comunidade ${ }^{40}$ (Baden-Powell, 1929, p.8).

Tendo explicitado esses domínios do escotismo depois de reconhecer a existência de organizações educacionais semelhantes, Baden-Powell (1939, p.127) observava a prerrogativa fundamental do movimento, comparando as habilidades e os valores interiorizados por meio das atividades escoteiras com o saber a ler e a escrever, que se aprendia na escola. Em particular, ele raciocinava que da mesma forma que a escola ensinava coisas que fora dela não se aprendia, no escotismo se aprenderia a virilidade, a vontade de ajudar outras pessoas, para salvar vidas ou para exercer serviços públicos de grande utilidade. Ou seja, o escotismo era o meio de fomentar virtudes que, tanto as relações sociais cotidianas, quanto aquelas entabuladas na escola, não conseguiriam desenvolver. A "escola de Baden-Powell” (Nascimento, 2008) faria frente à incapacidade social e escolar de cultivar valores para o bom funcionamento das instituições e para a realização de ambições econômicas e políticas de um ambiente imperialista. Incapacidades e limites vistos como superáveis na vida em pequenos grupos, próxima à natureza e plena em atividades corporais executadas pelos Boys Scouts.

\section{Considerações finais}

As críticas de Baden-Powell às práticas educacionais não devem desconsiderar a existência de um grande interesse pela educação moral e física nas décadas iniciais do século XX. Isso é importante para não esquecermos que Baden-Powell ecoava vozes de seu tempo, embora em sua escrita seja perceptível o sentimento de se estar lutando sozinho contra uma época que se negava a ver coisas cuja ubiquidade era-lhe inegável. Macleod (1983, p.111), ao destacar nos debates educacionais posicionamentos e nuances não considerados por Baden-Powell, observa que os "character builders", ao fazerem suas críticas, ignoravam alguns dos avanços no seio do escolanovismo e de outras tendências reconhecedoras do valor do trabalho mais individualizado com aluno. Entretanto, outras inovações, como a educação física, eram tidas como altamente valiosas. Particularmente nesse aspecto, o escotismo aproximava-se das direções assumidas pelas modernas teorias pedagógicas.

Desse modo, não há em Baden-Powell a preocupação de elaborar um pensamento educacional que considerasse o desenvolvimento da teoria e dos debates amplamente em curso no final do século XIX e início do XX. As suas críticas aos sistemas escolares eram constatações de alguém interessado em encontrar soluções para a crise moral então vista como existente, divulgando preceitos ou ignorados ou trabalhados, equivocadamente, nas escolas e nas famílias. Ele assumia suas proposições como educativas por considerá-las livres de formalismos e verbalismos, propondo formas prosaicas para se resolver problemas que educadores e políticos debatiam há séculos:

Nós pensamos que a melhor maneira de transmitir instruções teóricas era dá-las em pequenas parcelas com exemplos amplamente ilustrativos, sentados em volta da fogueira ou descansando, com demonstrações práticas antes do café da manhã. Uma palestra formal certamente aborrece aos rapazes $^{41}$ (Baden-Powell, 1908, p. 344). 
Childs (1995) raciocina que no contexto de expansão dos movimentos de jovens, as tentativas de controle e de doutrinamento, talvez, pudessem ser concebidas como de menor relevo, se comparadas ao fenômeno que, concretamente, teria contribuído para a amplitude do escotismo: o ímpeto ao consumo de lazer por parte dos jovens (p. 156). Dito de outra maneira, se não fosse o interesse nesse consumo por parte da juventude dos centros urbanos, talvez as intenções dos proponentes e sua retórica tivessem ecoado no vazio, fazendo a explícita vontade de criar um novo sistema de valores para os jovens ser "condenado ao fracasso" 42 (p. 156).

As ponderações de Macleod (1983) e de Childs (1995) chamam a atenção para o limite de se concluir análises sobre o escotismo, ou qualquer outro movimento educacional, pautando-se apenas no pensamento de seus idealizadores. Cientes dessa importante advertência e assumindo-a, igualmente, como uma limitadora das análises que agora encerramos, focalizamos o pensamento de Baden-Powell. Se esse pensamento, por si só, não pode explicar variados desdobramentos práticos e ideológicos observados no escotismo em escala planetária, também não possível desconsiderar que algumas das razões da grande receptividade e rapidez na expansão do movimento nas primeiras décadas do século XX, residem na forma e no conteúdo das práticas e justificativas propostas por Baden-Powell (Rosenthal, 1986).

O cerne da proposta era a reaproximação dos jovens à natureza por meio das atividades do corpo. $\mathrm{O}$ escotismo complementaria e remediaria a educação de sua época, avaliada como uma das fontes e dos endossos da decadência moral diagnosticada. Contra ela Baden-Powell redigiu suas obras. Sendo ideias dirigidas aos pais, aos professores e, principalmente, aos jovens, elas defendiam a necessidade de convencê-los à autoformação por meio da ação, da coragem, da saúde, da virilidade. Assim convencida, a juventude tomaria o rumo de uma sociedade livre do individualismo e do esfacelamento moral representado no "my safety first" e na falta de saúde e vigor corporal. A quem duvidasse das possibilidades de concretização desse ideal, os feitos e as virtudes de Baden-Powell, amplamente divulgadas por todo o mundo, comprovariam a viabilidade do projeto.

Finalizando, podemos afirmar que o escotismo e suas ideias fundadoras são de grande relevância para se pensar muitos dos dilemas que atingiram a educação intelectual, moral e corporal que inquietaram as sociedades nas primeiras décadas do século XX. Sublinhamos que na produção intelectual de Baden-Powell, ao lado do elogio das atividades corporais, aqui estudado, há outras facetas merecedoras de um cuidado mais detido por parte dos historiadores da educação.

\section{Referências}

BADEN-POWELL, Robert. Scouting for boys. London: H.Cox, 1908.

BADEN-POWELL, Robert. What Scouts can do: more yarns.1921

BADEN-POWELL, Robert. Rovering to success: a book o life-sport for young men. London: J. Jenkis, 1922.

BADEN-POWELL, Robert. Scouting and youth movements. London: Ernest Benn Limited, 1929.

BADEN-POWELL, Robert. Lessons from the varsity of life. 1933

BADEN-POWELL, Robert. Paddle your own canoe. London: Furnell and sons, 1939.

BAUBÉROT, Arnaud. Histoire du naturisme: le mythe du retour à la nature. Rennes: Presses Universitaires de Rennes, 2004. 
BLOWER, Bernard David. História do escotismo brasileiro. Rio de Janeiro: Centro Cultural do Movimento Escoteiro, 1994.

CHILDS, Michael J. Labour's apprentices: working-class lads in late victorian and edwardian England. Montreal: Mcgill-Queen’s University Press, 1995.

FERREIRA NETO, Amarílio; NEITZEL, Fernanda Mutz, (2006). "Didatics", games, scouts, physical, psychological and moral formation of a child. The FIEP bulletin, Foz do Iguaçú - PR, v. 76, n. I, p. 284-287. Disponível em http://www.proteoria.org/

Acesso em 21/08/2009

GABRIEL, Yara Cristina. Prescrições cívico-morais e a formação do cidadão: um estudo sobre a introdução do escotismo nas escolas públicas de São Paulo (1917-1922). Dissertação de mestrado, Mestrado em Educação: História, Política, Sociedade da PUCSP. São Paulo, 2003. 103p.

HEROLD JUNIOR, Carlos. A educação corporal no Paraná através do movimento escoteiro em Guarapuava (1927-1936). Educ. rev., Belo Horizonte, v. 27, n. 2, Aug. 2011. Available from <http://www.scielo.br/scielo.php?script=sci_arttext\&pid=S010246982011000200007\&lng=en\&nrm=iso>. access on $01 \quad$ Feb. 2012. http://dx.doi.org/10.1590/S0102-46982011000200007

JEAL, Tim. Baden-Powell: founder of the boy scouts. New Haven: Yale University Press, 2001.

LINHALES, Meily Assbú. A escola e o esporte: uma história de práticas culturais. São Paulo: Cortez, 2009.

MACDONALD, Robert H. Sons of the Empire: the Frontier and the Boy Scout Movement, 1890-1918. Toronto: University of Toronto Press, 1993.

MACLEOD, David. Building Character in the american boy: the boy scouts, YMCA, and their forerunners, 1870-1920. London: The University of Wisconsin Press, 1983.

NASCIMENTO, Adalson de Oliveira. Educação e civismo: movimento escoteiro em Minas Gerais (1926-1930). Revista Brasileira de História da Educação, 2004, n.7, p.4374.

NASCIMENTO, Jorge Carvalho do. A escola de Baden-Powell: cultura escoteira, associação voluntária e escotismo de estado no Brasil. Rio de Janeiro: Imago, 2008.

ROSENTHAL, Michael. The character factory: Baden-Powell and the origins of the boy scout movement. London: Collins, 1986.

PROCTOR, Tammy. "On my honour": Guides and Scouts in interwar Britain. Philadelphia: Transactions of the American Philosophical Society, 2002. v.92, part 2.

PUCHTA, Diogo Rodrigues, (2007). A formação do homem forte: educação física e gymnastica no ensino público primário paranaense (1882-1924). Dissertação de Mestrado. Curso de Pós-graduação em Educação da UFPR. Disponível em

http://dspace.c3sl.ufpr.br/dspace/bitstream/1884/13313/1/Disserta\%c3\%a7\%c3\%a3o\%20D iogo\%20Rodrigues\%20Puchta\%20Vers\%c3\%a3o\%20Final\%20Depositada.pdf Acesso em 23/05/2009.

SOUZA, Rosa Fátima de. A militarização da infância: expressões do nacionalismo na cultura brasileira. Cadernos CEDES, ano XX, n.52, 2000, p.104-121. 
SCHARADGRODSKY, Pablo Ariel. El scautismo em la educación física bonaerense: Argentina o acerca del buen encauzamiento varonil (1914-1916). Revista Brasileira de Ciências do Esporte, v.29, n.3, 2008,p. 155-177.

SOUZA, Rosa Fátima de. Alicerces da Pátria: história da escola primária no Estado de São Paulo (1890-1976). Campinas - SP: Mercado das Letras, 2009.

TABORDA DE OLIVEIRA, Marcus Aurélio. Educando pelo corpo: saberes e práticas na instrução pública primária paranaense (finais do séc. XIX, início do séc. XX). Anais do XV Conbrace e II Conice. 2007

Disponível em http://www.cbce.org.br/cd/resumos/222.pdf Acesso em 11/09/2009

THOMÉ, Nilson. Escotismo - caminho para novas emoções: apreciações sobre o Movimento Escoteiro enquanto prática educativa. Edição do autor: Caçador-SC, 2010.

THOMÉ, Nilson. Movimento escoteiro: projeto educativo extra-escolar, Revista HISTEDBR-Online, Campinas, n.23, 2006, p.171-194.

WATT, Carey. "No showy muscles": the boy scouts and the global dimension of physical culture and bodily health in Britain and colonial India. In: BLOCK, N.;PROCTOR, T. M. (orgs.) Scouting Frontiers: youth and the scout movement's first century. Newcastle upon Tyne: Cambridge Scholars Publishing, 2009.p.121-142.

ZUQUIM, Judith; CYTRYNOWICZ, Roney. Notas para uma história do escotismo no Brasil: a "psicologia escoteira" e a teoria do caráter como pedagogia de civismo. (19141937). Educação em Revista, Belo Horizonte, n.35, 2002, p.43-58.

Notas:

${ }^{1}$ Este trabalho contou com o apoio do CNPq.

${ }^{2}$ Todas as citações em língua estrangeira foram traduzidas livremente.

${ }^{3}$ Original: "Banden-Powell knew how to clothe abstract principles in engaging examples"

${ }^{4}$ Original: "The growth of Scouting was part of a worldwide tendency [...] to cope with rapid cultural change by inducting the young into a supervised world of recreation with prefabricated values"

${ }^{5}$ Original: "The period 1890 to 1914 saw an efflorescence of such organizations and institutions, catering to a successively broader range of youths and using increasingly subtler and more sophisticated methods to attract and hold the loyalty of boys"

${ }^{6}$ Original: "often did better at winning adult support than at holding boys".

${ }^{7}$ Para uma lista detalhada da produção bibliográfica de Baden-Powell, conferir Jeal (2001).

${ }^{8}$ Original: “... civilisation, with its town life, tram-cars, hot-and-cold water laid on, everything done for you, tends to make men soft and feckless beings"

${ }^{9}$ Original: "The public is largely occupied today with cinema-stars, Test Matches, Cup Finals and murders. This has been so, also, in the past; and it is thanks to this interest in false value that the nation is suffering today under its many ills. If the country is to throw off the disgrace that overshadows it, it must cleanse itself from its slums and from the misery and squalor among the mass of its people. It must help them in their total lack of religion and happiness. It must wake up to the need of truer education for the oncoming generation of citizens. The success or failure of our nation lies in the hands of those who are boys and girls today".

${ }^{10}$ Original: “... education has fresh difficulties to contend with today, in the shape of increased herd-instinct, undesirable teachings of a sensational Sunday press, immoral cinemas, and easy access to cheap, unhealthy pleasure, and gambling" 
11 Original: "With the modern extension of towns and villages and factories, of great tarred motor roads and telegraph, telephone and power lines over the face of the country, civilization is driving Nature farther and farther out of the reach of the majority, until realization of its beauties and wonders and our own affinity with God's creations, is becoming lost in the materialistic life of the crowd, with its depressing conditions of work and hectic search for pleasure among man-made squalid surroundings of bricks and mortar. The artificial is swamping out the natural in our life; thanks to motor-cars, bikes and elevators, our limbs, like our minds, will atrophy from want of exercise and our sons will grow brains instead of brawn".

${ }^{12}$ Original: "In our crowded, up-to-date centres we are fast becoming over-civilized. It has been said that in a few centuries our legs will have atrophied through complete dependence on tubes and trams and two penny buses. Our characters, too, will be non the better for having everything thought out and made easy for us, so that initiative, resourcefulness, self-reliance, pluck, chivalry, and other virtues will be no longer in demand. We shall be a nation of a table-fed jellyfish". The artificial is ousting the natural in most directions, and in few is this really good for us".

${ }^{13}$ A masturbação era veementemente condenada por Baden-Powell (Jeal, 2001; Baden-Powell, 1908).

${ }^{14}$ Original: "THE ROCKS - (Through herd temptation). Horses, betting and looking on at false sport. Wine, and other forms of self-indulgence. Women, dangers of a wrong attitude and blessings of the right one. Extremists in politics, in religion, etc.

15 Original: "Too much learning kills common sense", he wrote confidently, giving as his example the intuitive skill of the native bridge-builders of West Africa who could span a river in a fraction of the time taken by the British engineers using their "complex calculations". But the future prosperity of industrial nations would depend upon their scientists more than upon an army of self-reliant colonists or heroic explorers, however firm their muscles and sound their characters. This was the unpalatable truth which the Boy Scouts enabled so many men to ignore: brains in a modern society did matter more than character, whatever the Rhodes Scholarship examiners might decree. A civilization dominated by technology would only thrive with the help of men brought up to value science and learning rather than encouraged to despise it".

${ }^{16}$ Baden-Powell assumia algumas reivindicações femininas justas ou corretas, havendo aquelas que eram feitas pela diminuição da virilidade masculina. Jeal (2001) mostra que isso justificava a preocupação de separar os meninos das meninas nas práticas educacionais, pois o convívio entre meninos e meninas acabaria por feminizar os futuros homens.

17 Original: "With women now entering the professions and the suffragettes destroying that reassuring stereotype of the deferential gentlewoman, men were beginning to glimpse a future in which women would be able to do their jobs and there would be no room left for pursuits requiring strength and endurance. In America the new immigrants were out-breeding the old stock; was this the fault of better educated women, or was city "deterioration" sapping the virility of the nation's well-to-do urban men?"

${ }^{18}$ Original: "Les thèses évolutionnistes, par ailleurs, ont brisé l'image d'un corps immobile, se reproduisant à l'identique depuis la nuit des temps, pour en faire un objet mouvant, instable, susceptible de se transformer sous l'influence de son environnement"

${ }^{19}$ Original: Drinkers are a danger to the State. Prohibition will not be needed where th nation consists of men of character. The force of example. Over-smoking is a danger to health, as are also other forms of selfindulgence, such as Over-eating. Over-sleeping. Over-working. Physical fitness brings self-control and long life. Swearing is a sign of weak character.”.

${ }^{20}$ Original: At the beginning of the European War in 1914, two millions of our men joined up voluntarily. Six millions did not. One million were unable to, largely owning to physical defects from preventable causes.[...] Our aims in the Boy Scout (and Girl Guide) Movement is to develop both and to help the rising generation towards becoming efficient and happy citizens".

${ }^{21}$ Original: "Education is one great safeguard. By education I don't mean improved scholarship but education of mind and soul. The one enables you to pass by the danger; education of soul raises you far above it. If you expand your mind by giving yourself wider knowledge through travel and reading, through learning from the experiences of others, and from the study of nature, you will be safe against the call of the cuckoo; and if you expand you sould by giving yourself higher ideals and by giving to others your sympathy 
through good will and helpfulness you can never be much of a cuckoo yourself, or a "highbrow" as it is called in America; and you find yourself a better and a happier man".

22 Original: "The teachers cannot hope, in the time available, to do more then show the children the elements and inculcate into them the desire and the method of learning for themselves. The teacher of today fully recognises the necessity for character-training, but is handicapped by the impossibility of teaching character to a large class. Character-training is a matter of ascertaining and developing to the best of the teacher's ability such special germ for good as exists in each individual child; but the harassed teacher of a class of from forty to sixty children cannot hope to deal with them otherwise than in the mass".

${ }^{23}$ Importante não esquecer que o escotismo também se utilizava dos desfiles. Porém, Baden-Powell (1929) sublinhava que a utilização das marchas e da organização militar ao movimentar as tropas, não era a parte principal do escotismo, sendo adotadas, apenas, para realizar os deslocamentos de modo mais organizado.

${ }^{24}$ Original: “...estimable young men, able to read and write, well-behaved and amenable to discipline, and easily made into smart-looking parade soldiers - but without individuality or strength of character, utterly without resourcefulness, initiative or the guts for adventure. Modern conditions of life with its artificiality were making them members of the herd with everything being done for them and with the fetish of "safety first" ever before their eyes".

${ }^{25}$ Original: "The school education of girls had been put on a higher and steadily improving footing, but the problem of their character training was yet unsolved. Character cannot be taught in a class. It has, necessarily, to be expanded in the individual, and largely by effort on the part of the pupil herself".

${ }^{26}$ Original: "Common sense is almost the most useful and valuable thing you have got in your character. The pity of it is that so few fellow know this or make use of it! They prefer to be guided by what they see written in books instead of using their own wits"

27 Original: This combination of the anti-intellectual and the anti-urban dovetailed with Baden-Powell's criticism of schools for negleting their boys'physical and moral development..."

${ }^{28}$ Original: "There is a great deal of nonsense in fashion in the way of bodily exercises; so many people seem to think that their only object is to make huge muscle".

${ }^{29}$ Original: "To impose both Greek and Latin grammar on young boys not a bit interested in them seems to me as stupid a waste of time as making unmusical girls spend endless hours in learning to play scales on the piano. I know that I am displaying my ignorance of the science and theory of education by saying this, but I am merely speaking from results I have seen in the world".

${ }^{30}$ Original: "If we look at the amount of public money that is spent every year on education, and then look at the proportion of ill-health, preventable disease, infant mortality, crime, unemployment, unemployability and thriftless poverty, which no amount of public money can remedy, prevailing in the population at the present time, in all honesty we must admit that the end of education has not yet been attained. [...] Perhaps education even a decade or two ago - of which we are seeing the results today - tended too much towards scholastic attainment and too little toward being a preparation for life. It is education for life that is needed, since scholastic attainments help only the comparatively few, while life has to be lived by every individual born into the world. Education still tends to prepare boys and girls for the standard of examination rather than for the needs of life; and by life is meant not merely how to make a living, but rather how to live - how to enjoy and take the best use of life, and to be happy and useful".

${ }^{31}$ Original: "Education progress and improvement have developed in the half century since I was at school, but traditional methods die hard, and they fail to produce so many able leaders or social servants as they should do out of the thousands of young men that the schools send into the world each year"

32 Original: "ANTIDOTES. (Through individual effort). Active Hobbies and earning money. Self-Control and character. Chivalry and health of mind and body. Service for your fellow-men and for God".

${ }^{33}$ Original: "In addition to what I learned in school - which wasn't and overwhelming lot - there was a great deal that I learned at school, outside the classroom, which was of value time. Also I learned more still in my holidays, from my brothers".

${ }^{34}$ Original: "You often see it said that the Public School education with the more well-to-do boys get it so good. It is good, but not so much for what is taught in the class-room as for what is learnt on the playing field and out of school". 
${ }^{35}$ Original: "One cause which contributed to the downfall of the Roman Empire was the fact that the soldiers fell away from the standard of their forefathers in bodily strength".

${ }^{36}$ Original: "Unfortunately, for the ordinary boy in civilised countries, there is nothing of this kind. We badly need some such training for our lads if we are to keep up manliness in our race instead of lapsing into a nation of soft, sloppy, cigarette-suckers".

${ }^{37}$ Original: Education has no wider outlook than making scholars. [...]Christianity or broad-minded lovepractice does not yet prevail in his world. In the Boy Scout and Girl Guide movement we are making the attempt to oust selfulness by inculcating in the young a wider vision and mutual goodwill and service. We don't pretend that Scouting will do the trick, but since it has caught on with such an extraordinary rapidity as a brother hood in so many different countries, irrespective of class, creed or race, one may hope that at any rate it is a definite step in the desired direction.

${ }^{38}$ Original: This scheme may, I hope, supply an additional means by which to get hold of the more unruly boys and to continue out of hours the practice of the theory which they have learnt in school. Unrully boys are often the best, once you have got the right side of them. A commision on our schools has recently shown that there is an excess of book instruction in many of them; possibly if one day a week were devoted to scouting it would greatly benefit both the teachers and the scholars mentally and physically".

${ }^{39}$ Original: Remember that on leaving school you have not been educated fully to become a man. Mainly you have been shown how to learn. If you want to win success, you must now finish your education by educating yourself. I suggest that this should take three main direction: of your profession or trade, as a future father of children, as citizen and leader of other men. When I left school I found that I was, as it were, in a dark room, and the education I had been given was as a lighted match which showed how dark the room was, but that a candle was available for me to light with that match and use for my future guidance in the room

${ }^{40}$ Original: "In the Boy Scouts training we are endeavouring to fill some of these chinks. The main ones which we found open were: 1) Character - That is, manliness, sense of honour and balanced, broadminded outlook. 2) Physical health and care of the body with temperance and chastity.3) Handcrafts and co-operation of hand with brain. 4) Service for other and the community".

${ }^{41}$ Original: "We found the best way of imparting theoretical instruction was to give it out in short installments with ample illustrative examples when sitting round the campfire or otherwise resting, and with demonstrations in the practice hour before breakfast. A formal lecture is apt to bore the boys".

${ }^{42}$ Original: "...doomed to failure".

Recebido em abril/2012

Aprovado em setembro/2012 